\title{
Ventilatory response to exercise in patients after correction of cyanotic congenital heart disease: relation with clinical outcome after surgery
}

\author{
T Reybrouck, D Boshoff, L Vanhees, J Defoor, M Gewillig
}

Heart 2004;90:215-216. doi: 10.1136/hrt.2002.005918

$\mathrm{P}$ atients with congenital heart disease can usually perform low intensity exercise as well as healthy peers, but often have difficulty in reaching maximal exercise intensity. However, formal exercise testing has repeatedly shown impaired values for cardiorespiratory exercise performance. ${ }^{1}$ A considerable number of patients may complain of exercise intolerance and dyspnoea at heavy intensities of exercise.

The aim of this study was to assess the efficiency of the ventilatory response to exercise by means of breath by breath analysis of gas exchange. Special attention was paid to total ventilation and alveolar ventilation as the difference between these values reflects the physiological dead space ventilation $(\dot{V} D)$, and is used as an index of ventilatory efficiency during exercise. More specifically, we assessed how the ventilatory response during exercise was affected by the clinical result of surgery and whether this correlated with the functional status after surgery for congenital heart disease.

To study whether an inefficient ventilatory response to exercise could be related to the effect of a sternotomy, the ventilatory response to exercise in the present group of patients was compared with a group of age matched patients who had also undergone sternotomy for surgical closure of a ventricular septal defect (VSD).

\section{PATIENTS AND METHODS}

One hundred and six patients were used for this analysis. At a routine outpatient visit, the patients were clinically assessed, and also underwent echocardiographic, electrocardiographic, and radiological examinations. Three patient categories with previous surgical repair for cyanotic congenital heart disease were studied: total repair for tetralogy of Fallot $(\mathrm{n}=34)$, atrial switch operation for transposition of the great arteries (TGA) $(n=23)$, and Fontan operation for functionally univentricular hearts (Fontan) $(n=13)$. These patient groups were compared to a group of age matched normal controls $(n=16)$ and 20 patients with VSD-PO. The average age at testing was 12.6 (2.3) years $(p>0.25$ for comparison between groups).

The methods for exercise testing have been described previously. $^{2}$ Exercise testing was performed on a treadmill (speed set at $5.6 \mathrm{~km} / \mathrm{h}$; inclination increased by $2 \%$ every minute, until a target heart rate of 170 beats/min). Gas exchange was measured on a breath by breath basis using mass spectrometry. Ventilatory efficiency was determined by assessment of total ventilation $\left(\dot{\mathrm{V}}_{\mathrm{E}}\right)$, alveolar ventilation $\left(\dot{\mathrm{V}}_{\mathrm{A}}\right)$, and the physiological dead space ventilation $\left(\dot{\mathrm{V}}_{\mathrm{E}}-\dot{\mathrm{V}}_{\mathrm{A}}\right)$, and further by calculation of the slope of minute ventilation versus carbon dioxide output. Slopes were calculated until a heart rate of 170 beats/min was reached. The normal values were defined as $95 \%$ confidence intervals of the mean value obtained in normal controls. The data are presented as mean (SD).

\section{RESULTS}

A significantly elevated value for total $\dot{\mathrm{V}}_{\mathrm{E}}(\mathrm{p}=0.001)$ (range $23-48 \%$ ) was found at different exercise levels, when compared to normal controls. This resulted from a significantly higher value of both alveolar $(p=0.03)$ and physiological dead space ventilation $(p=0.01)$ compared to normal controls. This larger difference between total and alveolar ventilation varied from $12-48 \%$ at different levels of exercise. The largest differences ( $\dot{\mathrm{V} D}=9 \mathrm{l} / \mathrm{min}$ ) were found in patients with TGA and in patients with Fontan circulation at $8 \%$ inclination of the treadmill. Abnormal values for the physiological dead space ventilation ( $>95 \%$ confidence limit of the normal mean value for at least four exercise levels) were found in a considerable number of patients in all three groups (table 1). The inefficient ventilatory response to exercise in the patients was also characterised by significantly higher than normal values $(p<0.05)$ for the ventilation versus carbon dioxide slope.

Furthermore, to study the possible effect of thoracic surgery on the efficiency of gas exchange during exercise, we compared the results obtained in a group of patients with surgical closure of VSD via sternotomy, to the other groups. In patients with surgically closed VSD the slope of $\dot{V}_{\mathrm{E}}$ versus $\dot{\mathrm{V}} \mathrm{CO}_{2}$ averaged $32.2(6.4)$ and was not significantly different from the normal controls $(31.5(8.2))(p=0.25)$. The incidence of abnormal values for physiological dead space ventilation $(\dot{V} D)$ was associated with a significantly higher number of residual haemodynamic lesions (33-62\%) $(\mathrm{p}<0.05)$, compared to patients with normal values (12-28\%) (table 1).

\section{DISCUSSION}

Surgical results of congenital heart disease are excellent nowadays, with the majority of the patients leading a normal life. ${ }^{3}$ This is confirmed by the exercise results in the present study: $33-50 \%$ of the patients have a perfectly normal ventilatory response during exercise. The purpose of the present study was to evaluate whether the inefficient ventilatory response to exercise, as observed in a considerable number of patients, was associated with haemodynamic abnormalities after surgery. In $32-62 \%$ of the patients with an inefficient ventilatory response to exercise, residual haemodynamic lesions after surgery were observed. Typical lesions were right ventricular dilatation and pulmonary incompetence or stenosis in TF patients, severe right ventricular dilatation and tricuspid incompetence in patients

\footnotetext{
Abbreviations: TGA, transposition of the great arteries; $\dot{\mathrm{V}}_{\mathrm{A}}$, alveolar ventilation; $\dot{V} D$, dead space ventilation; $\dot{V}_{\mathrm{E}}$, total ventilation; $V S D$, ventricular septal defect
} 
Table 1 Incidence of abnormal values for physiological dead space ventilation $\dot{V} \mathrm{D}$ and $\dot{V}_{\mathrm{E}}$ versus $\dot{\mathrm{V}} \mathrm{CO}_{2}$ slope. Associated haemodynamic lesions in patients with surgical repair of cyanotic congenital heart disease are also shown

\begin{tabular}{|c|c|c|c|c|c|c|}
\hline \multirow[b]{2}{*}{ Diagnosis } & \multicolumn{4}{|l|}{ Incidence } & \multicolumn{2}{|l|}{ Associated lesions } \\
\hline & Normal VD & Normal slope $\dot{\mathrm{V}}_{\mathrm{E}} \vee \dot{\mathrm{V}} \mathrm{CO}_{2}$ & Abnormal VD & Abnormal slope $\dot{\mathrm{V}}_{\mathrm{E}} \vee \dot{\mathrm{V}} \mathrm{co}_{2}$ & Abnormal VD & Normal VD \\
\hline $\operatorname{TF}(n=34)$ & $18(53 \%)$ & $23(68 \%)$ & $16(47 \%)$ & $11(32 \%)$ & $\begin{array}{l}\text { PR } 10 / 16(62 \%)^{*} \\
\text { PS } 8 / 16(50 \%)^{*}\end{array}$ & $\begin{array}{l}\text { PR 5/18 (28\%) } \\
\text { PS 3/18 (17\%) }\end{array}$ \\
\hline TGA $(n=23)$ & $8(35 \%)$ & $8(39 \%)$ & $15(65 \%)$ & $14(61 \%)$ & RV dil+TI 5/15 (33\%)* & $\begin{array}{l}\text { RV dil+TI 1/18 } \\
(12 \%)\end{array}$ \\
\hline Fontan $(n=13)$ & $5(38 \%)$ & $5(38 \%)$ & $8(62 \%)$ & $8(62 \%)$ & $\begin{array}{l}\text { AV valve insuf } 8 / 13 \\
(61 \%)^{*}\end{array}$ & $\begin{array}{l}\text { AV valve insuf } 1 / 5 \\
(20 \%)\end{array}$ \\
\hline
\end{tabular}

${ }^{*} \mathrm{p}<0.05$

Abnormal values are defined as values which exceeded the $95 \%$ confidence limits of the normal mean value. The incidence of subnormal values was significantly higher in all patient groups $\left(\chi^{2}: p<0.0001\right)$ compared to normal controls.

$A V$ valve insuf, atrioventricular insufficiency; $P R$, pulmonary regurgitation; $\mathrm{PS}$, pulmonary stenosis; $\mathrm{RV}$ dil, right ventricular dilatation; slope $\dot{\mathrm{V}}_{\mathrm{E}} \mathrm{V} \dot{\mathrm{V}}_{\mathrm{CO}_{2}}$, slope of ventilation versus carbon dioxide output; TI, tricuspid incompetence; VD, physiological dead space ventilation.

with Senning operation, and atrioventricular insufficiency in patients with Fontan circulation.

The elevated value for physiological dead space ventilation and the increased ratio of ventilation over $\dot{\mathrm{V}} \mathrm{CO}_{2}$, as observed in about half of the patients, suggest a ventilation/perfusion mismatch. This can be attributed to an inability to appropriately increase the effective pulmonary blood flow in response to increasing metabolic needs. ${ }^{4}$

Concern could be raised about be the effect of thoracic surgery on the ventilatory efficiency during exercise. Previous studies have shown restrictive lung function patterns in patients who underwent palliation or definitive repair of tetralogy of Fallot. ${ }^{5}$ Therefore, we compared the ventilatory efficiency of patients with repair of cyanotic congenital heart disease, to patients who underwent thoracic surgery for noncyanotic congenital heart disease such as surgical closure of a VSD. In the group of patients after VSD closure, no significant difference was found for ventilatory efficiency with normal controls. Therefore, the increased values for physiological dead space ventilation and slope of $\dot{\mathrm{V}}_{\mathrm{E}}$ versus $\dot{\mathrm{V}} \mathrm{CO}_{2}$ after surgery for cyanotic congenital heart disease cannot be ascribed to the effect of previous thoracic surgery.

Assessment of the functional status after surgery by anamnesis and evaluation of the medical history is unreliable and lacks sensitivity in patients with congenital heart disease. We would therefore recommend that exercise testing with direct measurements of gas exchange should be performed in these patients as this contributes to global functional evaluation.

\section{ACKNOWLEDGEMENTS}

This study was supported in part by grants from the National Foundation for Research in Paediatric Cardiology. J Defoor is
Research Assistant of the fund for Scientific Research, Flanders, Belgium (F.W.O. - Vlaanderen). We gratefully acknowledge the help of Dirk Schepers MS, during the statistical analysis of the data.

\section{Authors' affiliations}

T Reybrouck*, D Boshoff, M Gewillig, Department of Congenital and Paediatric Cardiology, University Hospital Gasthuisberg, Leuven, Belgium

L Vanhees, J Defoor, Cardiovascular Rehabilitation Unit, Department of Rehabilitation Sciences, University of Leuven, Leuven, Belgium

*Also Cardiovascular Rehabilitation Unit, Department of Rehabilitation Sciences, University of Leuven

Correspondence to: Professor Tony Reybrouck, Department of Congenital and Paediatric Cardiology, University Hospital Gasthuisberg, Herestraat, 3000 Leuven, Belgium; tony.reybrouck@uz.kuleuven.ac.be

Accepted 11 August 2003

\section{REFERENCES}

1 Driscoll D, Robert R, Wolfe, et al. Cardiorespiratory responses to exercise of patients with aortic stenosis, pulmonary stenosis and ventricular septal defect. Circulation 1993;87(suppl I):1102-3.

2 Reybrouck T, Mertens L, Brusselle S, et al. M. Oxygen uptake versus exercise intensity: a new concept in assessing cardiovascular exercise function in patients with congenital heart disease, Heart 2000;84:46-52.

3 Deanfield J, Thaulow E, Warnes C, et al. Management of grown-up congenital heart disease. Eur Heart J 2003;24:1035-84.

4 Gilljam T, Eriksson BO, Sixt R. Cardiac output and pulmonary gas exchange at maximal exercise after atrial redirection for complete transposition. Eur Heart $J$ 1998; 19:1865-64.

5 Wessel HU, Paul MH. Exercise studies in tetralogy of Fallot: a review. Pediatr Cardiol 1999;20:39-47. 